\title{
Degradation of azo dye acid red B on manganese dioxide in the absence and presence of ultrasonic irradiation
}

\author{
Jiantuan Ge, Jiuhui Qu* \\ State Key Laboratory of Environmental Aquatic Chemistry, Research Center for Eco-Environmental \\ Sciences, Chinese Academy of Sciences, Beijing 100085, China
}

Received 25 October 2002; received in revised form 18 March 2003; accepted 19 March 2003

\begin{abstract}
Degradation of azo dye acid red $\mathrm{B}(\mathrm{ARB})$ on $\mathrm{MnO}_{2}$ in the absence and presence of ultrasonic irradiation (sonication) has been investigated. The effect of initial $\mathrm{pH}$, anions $\left(\mathrm{Cl}^{-}, \mathrm{NO}_{3}{ }^{-}, \mathrm{SO}_{4}{ }^{2-}\right)$, and saturated gas (argon/oxygen) has been studied. The experimental results show that decolorization of the dye on $\mathrm{MnO}_{2}$ is highly $\mathrm{pH}$ dependent, with increasing decolorization efficiencies at decreasing $\mathrm{pH}$ values. The $\mathrm{SO}_{4}{ }^{2-}$ and $\mathrm{NO}_{3}{ }^{-}$ions are observed to suppress the adsorption of $\mathrm{ARB}$ on $\mathrm{MnO}_{2}$ dramatically, suggesting competitive nature with the dye. Sonication accelerates decolorization and mineralization of the dye. And oxygen used as saturated gas is more favorable for mineralization of the dye than argon. The average particle diameter of $\mathrm{MnO}_{2}$ decreases from 47.5 to $3.19 \mu \mathrm{m}$ after sonication.
\end{abstract}

(C) 2003 Elsevier Science B.V. All rights reserved.

Keywords: Manganese dioxide; Sonochemistry; Acid red B; Decolorization; Mineralization

\section{Introduction}

Azo dyes constitute the largest class of dyes used in industry. In the textile industry, it is estimated that $10-15 \%$ of the dye is lost during the dyeing process and released as effluent. Azo dyes are resistant to aerobic degradation; however, under anaerobic conditions, the azo linkage is reduced to generate aromatic amines that are colorless but can also be toxic and potentially carcinogenic.

The conventional treatment methods for eliminating dyes from the waste stream include flocculation with lime, activated charcoal adsorption, and biotreatment. Lime treatment and

\footnotetext{
* Corresponding author. Tel.: +86-10-62849137; fax: +86-10-62849160.

E-mail address: jhqu@mail.rcees.ac.cn (J. Qu).
} 
charcoal adsorption generate large amount of solid wastes, which require costly disposal and regeneration methods. Biotreatment processes rely on indigenous soil microorganisms to degrade dye compounds. Since the synthetic dyes are resistant to aerobic biodegradation, this process is likely to be insufficient. Thus, there is a need for developing treatment technologies that are more effective in eliminating dyes from the waste stream at its source.

Advanced oxidation processes (AOPs), based on the chemical, photochemical and photocatalytic production of hydroxyl radicals $\left({ }^{\bullet} \mathrm{OH}\right)$, which act as strong oxidizing agents, have emerged as a promising technology for the degradation of organic pollutants. The methods for generating hydroxyl radicals are diverse, ranging from homogeneous oxidation such as $\mathrm{H}_{2} \mathrm{O}_{2} / \mathrm{Fe}^{2+}$ [1] and $\mathrm{UV} / \mathrm{O}_{3}$ [2] to heterogeneous photocatalysis involving illumination of large bandgap semiconductor particulates either dispersed in slurries or immobilized on films [3,4]. While photocatalysis has been studied extensively, its commercialization has yet not been realized and barriers prevail [5-7]. Additionally, there is some interest in on-stream ozonation and chlorination treatment processes, environmental problems associated with both chlorine and ozone render both unattractive.

Sonochemical degradation of organic pollutants has received increasing attention in recent years [8-14]. The chemical effects of high-intensity ultrasound result primarily from acoustic cavitation: the formation, growth, and implosive collapse of bubbles in liquids [15]. Acoustic cavitation generates sites of locally high temperatures and pressures for short period of time, which give rise to the $\mathrm{H}_{2} \mathrm{O}$ sonolysis with production of radical species $\left(\mathrm{H}^{\bullet}\right.$, $\left.\bullet \mathrm{OH}, \mathrm{HOO}^{\bullet}\right)$ and direct destruction of solute $[9,16,17]$. However, little information is available on heterogeneous sonochemical degradation of organic pollutants.

Manganese oxides exhibit considerable activity in oxidation-reduction reactions due to the presence of manganese ions with different oxidation states. Unfortunately, it has been shown that manganese oxides are insoluble $[18,19]$. However, the amount of manganese dissolved in solution can be increased considerably in acidic medium with the addition of organic compounds such as dyes [20]. But the further adsorption and oxidation of dye compound on the mineral particles interface reduce their surface areas and lead to inhibition of the process [21].

In this work, decolorization of azo dye acid red B (ARB) in the absence and presence of ultrasound is investigated. The motivation of this work is to investigate the feasibility of degradation organic pollutants in heterogeneous sonochemical reactions.

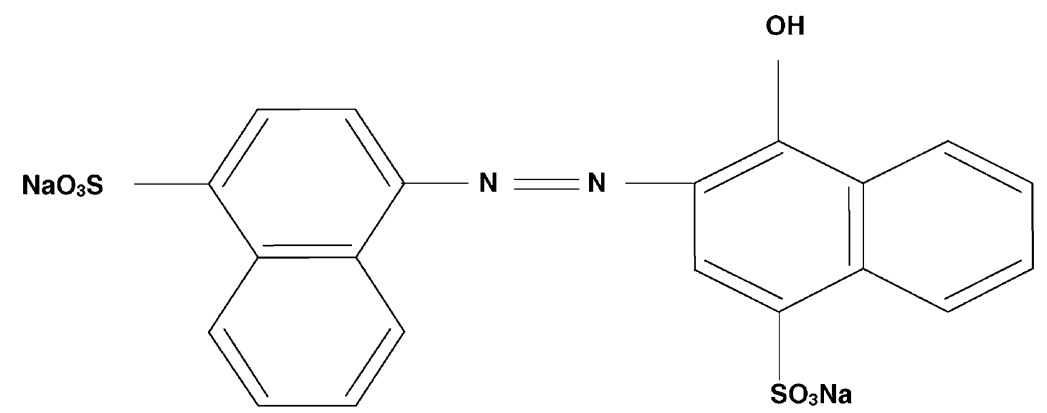




\section{Materials and methods}

\subsection{Materials}

Manganese dioxide of analytical reagent grade was supplied by Shanghai Chemical Reagents Company. Acid red B was purchased from Beijing Qinghe Knitting Mill and used without further purification. Stock solution $(2000 \mathrm{mg} / \mathrm{l})$ of the dye was prepared with deionized water, and further diluted to various concentrations in the experiment. All the other chemicals used in this study were of analytical reagent grade. Argon and oxygen gases were of purity $>99.99 \%$.

\subsection{Analyses}

The surface area of $\mathrm{MnO}_{2}$ was determined by Brunauer-Emmett-Teller measurements (BET) using nitrogen gas and a multipoint method on a Micromeritics accelerated surface area and porosimetry (ASAP) 2000. The surface area of the $\mathrm{MnO}_{2}$ is $29.3 \mathrm{~m}^{2} / \mathrm{g}$. The particle size of $\mathrm{MnO}_{2}$ in the suspension was recorded on a Mastersizer 2000 Laser Particle Analyzer (Malven).

The aliquots were collected at timed intervals and filtrated through a $0.2 \mu \mathrm{m}$ syringe-end filter. The concentration of the dye in the filtrate was determined using UV-Vis Spectrophotometer (Hitachi Model 3010) at $515 \mathrm{~nm}$. Total organic carbon (TOC) measurements were performed on a Shimadzu TOC Analyzer Model 500. Dissolved manganese was determined on a Hitachi Model Z-6100 atomic absorption spectrophotometer. The zeta potential was recorded on a Zetasizer Model 2000 (Malven).

\subsection{Experimental procedures}

Decolorization experiments of $\mathrm{ARB}$ on $\mathrm{MnO}_{2}$ in the absence of ultrasonic irradiation were carried out in batch mode. A $100 \mathrm{ml}$ volume of dye solution, previously adjusted to a fixed $\mathrm{pH}$ value with diluted $\mathrm{NaOH}$ and $\mathrm{HCl}, \mathrm{HNO}_{3}$ or $\mathrm{H}_{2} \mathrm{SO}_{4}$, respectively, was added to a $250 \mathrm{ml}$ beaker containing different amount of $\mathrm{MnO}_{2}$. The suspensions were immediately shaken in an air-bath $\left(25 \pm 1{ }^{\circ} \mathrm{C}, 150 \mathrm{rpm}\right)$ (Model HZQ-C) for $4 \mathrm{~h}$.

The sonochemical experiments were carried out in a Branson $\mathrm{S} 3200(50 \mathrm{kHz}, 150 \mathrm{~W})$ ultrasonic cleaning bath. Thermostating was done using coolant passed through copper coils (outer diameter $6 \mathrm{~mm}$ ) suspending in the bath connected with a thermostat. The temperature of the bath was kept at $\sim 22{ }^{\circ} \mathrm{C}$. A $250 \mathrm{ml}$ conical glass reactor with a plane bottom of thin glass in order to minimize sonic absorption and to ensure good heat exchange with the water bath was fitted at a constant position. The initial concentration of ARB was $100 \mathrm{mg} / \mathrm{l}$ and the volume exposed to sonication was $100 \mathrm{ml}$. The $\mathrm{pH}$ of the solution was adjusted to 3.0 with diluted $\mathrm{NaOH}$ and $\mathrm{H}_{2} \mathrm{SO}_{4}$. The suspension was stirred with a mechanical stirrer to ensure good liquid-solid mass transfer. At timed intervals, $5 \mathrm{ml}$ of suspension was withdrawn with a syringe. Then the sample was immediately filtrated through a $0.2 \mu \mathrm{m}$ filter for analysis of absorbance, dissolved manganese and TOC. The control experiment was performed without sonication under argon atmosphere; other experimental conditions were the same as above. 
During the entire process, $\mathrm{pH}$ was not readjusted and no buffer solution was used.

\section{Results and discussion}

The dye effluents are generally characteristic of strong $\mathrm{pH}$ and anions variations. The $\mathrm{pH}$, which results in modification of the physical properties (including charge) of molecules with ionisable functional groups, plays an important role in the adsorption and oxidation of ARB on $\mathrm{MnO}_{2}$. Therefore, both $\mathrm{pH}$ and anions were chosen as the main factors in the present study.

\subsection{Effect of $\mathrm{pH}$ on the decolorization of $A R B$ in the absence of sonication}

The decolorization efficiency of $\mathrm{ARB}$ on $\mathrm{MnO}_{2}$ in the absence of ultrasound irradiation at different $\mathrm{pH}$ levels was shown in Fig. 1. The $\mathrm{pH}$ of the solution was adjusted with diluted $\mathrm{NaOH}$ and $\mathrm{HCl}$. It was found that the decolorization of the dye over $\mathrm{MnO}_{2}$ was highly $\mathrm{pH}$ dependent, with the decolorization efficiencies increased with decreasing $\mathrm{pH}$ values. At $\mathrm{pH}$ $>10$, the decolorization of the dye was negligible. Both the surface charge of $\mathrm{MnO}_{2}$ and the solution speciation of ARB $\left(\mathrm{H}_{2} \mathrm{~L}\right)$ changed with $\mathrm{pH}$. Protonation of the oxide surface and azo dye as a function of $\mathrm{pH}$ may be represented as follows:

$$
\begin{array}{ll}
\mathrm{H}_{2} \mathrm{~L} \leftrightarrow \mathrm{HL}^{-}+\mathrm{H}^{+} & k_{\mathrm{a} 1}=\frac{\left[\mathrm{HL}^{-}\right]\left[\mathrm{H}^{+}\right]}{\left[\mathrm{H}_{2} \mathrm{~L}\right]} \\
\mathrm{HL}^{-} \leftrightarrow \mathrm{L}^{2-}+\mathrm{H}^{+} & k_{\mathrm{a} 2}=\frac{\left[\mathrm{L}^{2-}\right]\left[\mathrm{H}^{+}\right]}{\left[\mathrm{HL}^{-}\right]}
\end{array}
$$

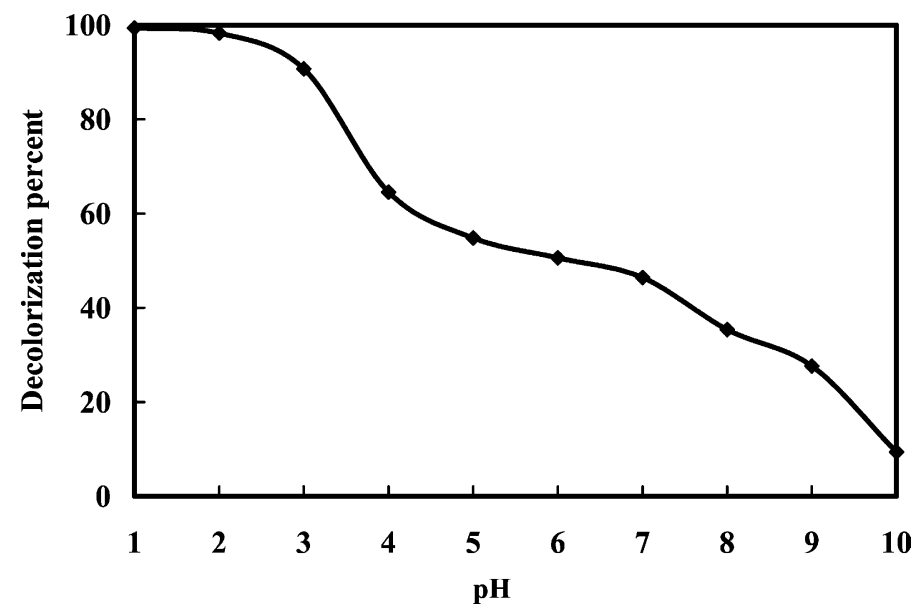

Fig. 1. Effect of $\mathrm{pH}$ on $\mathrm{ARB}$ adsorption on $\mathrm{MnO}_{2}(2 \mathrm{~g} / \mathrm{l})$ in the absence of sonication, initial $\mathrm{pH}$ adjusted to 3.0 with diluted $\mathrm{NaOH}$ and $\mathrm{HCl}$. 


$$
\begin{aligned}
& >\mathrm{MnOH}_{2}{ }^{+} \leftrightarrow>\mathrm{MnOH}+\mathrm{H}^{+} \quad K_{\mathrm{a} 1}=\frac{[>\mathrm{MnOH}]\left[\mathrm{H}^{+}\right]}{\left[>\mathrm{MnOH}_{2}{ }^{+}\right]} \\
& >\mathrm{MnOH} \leftrightarrow>\mathrm{MnO}^{-}+\mathrm{H}^{+} \quad K_{\mathrm{a} 2}=\frac{\left[>\mathrm{MnO}^{-}\right]\left[\mathrm{H}^{+}\right]}{[>\mathrm{MnOH}]}
\end{aligned}
$$

The oxidation of organic compounds on manganese oxide may be described involving the diffusion of organic compound to the particle surface to first form a complex, followed by exchange of electrons with the reactive surface of $\mathrm{MnO}_{2}$ [22]. For ARB, as a hydrophilic substrate, the neutral species more easily diffuse to and accumulate at the surface of $\mathrm{MnO}_{2}$ in comparison with its corresponding ionic forms. The decolorization efficiency remarkably increased as the $\mathrm{pH}$ decreased from 4 to 3 . One possible explanation is that the reaction due to electrostatic attraction between the predominant protonation level species $\mathrm{HL}^{-}$and $\mathrm{MnOH}_{2}{ }^{+}$readily takes place in this $\mathrm{pH}$ range as follows:

$$
\begin{aligned}
& >\mathrm{MnOH}_{2}{ }^{+}+\mathrm{HL}^{-} \leftrightarrow>\mathrm{MnL}^{-}+\mathrm{H}_{2} \mathrm{O}+\mathrm{H}^{+} \quad K_{\mathrm{a} 3}=\frac{\left[>\mathrm{MnL}^{-}\right]\left[\mathrm{H}^{+}\right]}{\left[>\mathrm{MnOH}_{2}{ }^{+}\right]\left[\mathrm{HL}^{-}\right]} \\
& >\mathrm{MnOH}_{2}{ }^{+}+\mathrm{H}_{2} \mathrm{~L} \leftrightarrow>\mathrm{MnHL}+\mathrm{H}_{2} \mathrm{O}+\mathrm{H}^{+} \quad K_{\mathrm{a} 3}=\frac{\left.[>\mathrm{MnHL}] \mathrm{H}^{+}\right]}{\left[>\mathrm{MnOH}_{2}+\right]\left[\mathrm{H}_{2} \mathrm{~L}\right]}
\end{aligned}
$$

The zeta potential profile of the $\mathrm{ARB} / \mathrm{MnO}_{2}$ suspension shown in Fig. 2 may further prove the above explanation to some extent. The fluctuation of decolorization occurred near $\mathrm{pH} 3$, where is the point of zero charge (PZC) of $\mathrm{MnO}_{2}$ [23]. Hence, the oxidizing ability of $\mathrm{MnO}_{2}$ can be sharply enhanced [22].

\subsection{Effect of anions on the decolorization of ARB in the absence of sonication}

It was very interesting to find out in this study that counteranions such as $\mathrm{Cl}^{-}, \mathrm{NO}_{3}{ }^{-}$and $\mathrm{SO}_{4}{ }^{2-}$, even at very low concentrations, strongly affected the decolorization of ARB on $\mathrm{MnO}_{2}$, especially at high ARB concentrations (Fig. 3). In these cases, solutions of different

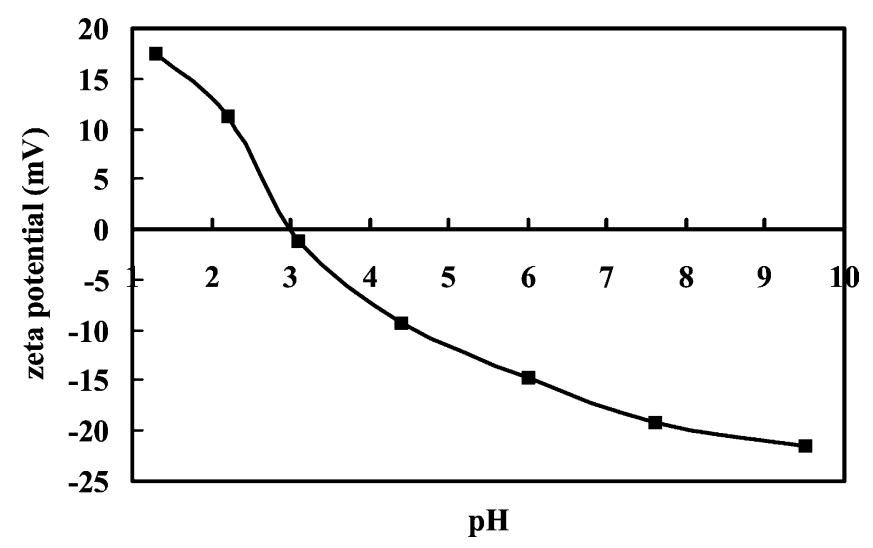

Fig. 2. Zeta potential of $\mathrm{ARB} / \mathrm{MnO}_{2}$ as a function of solution $\mathrm{pH}$. 


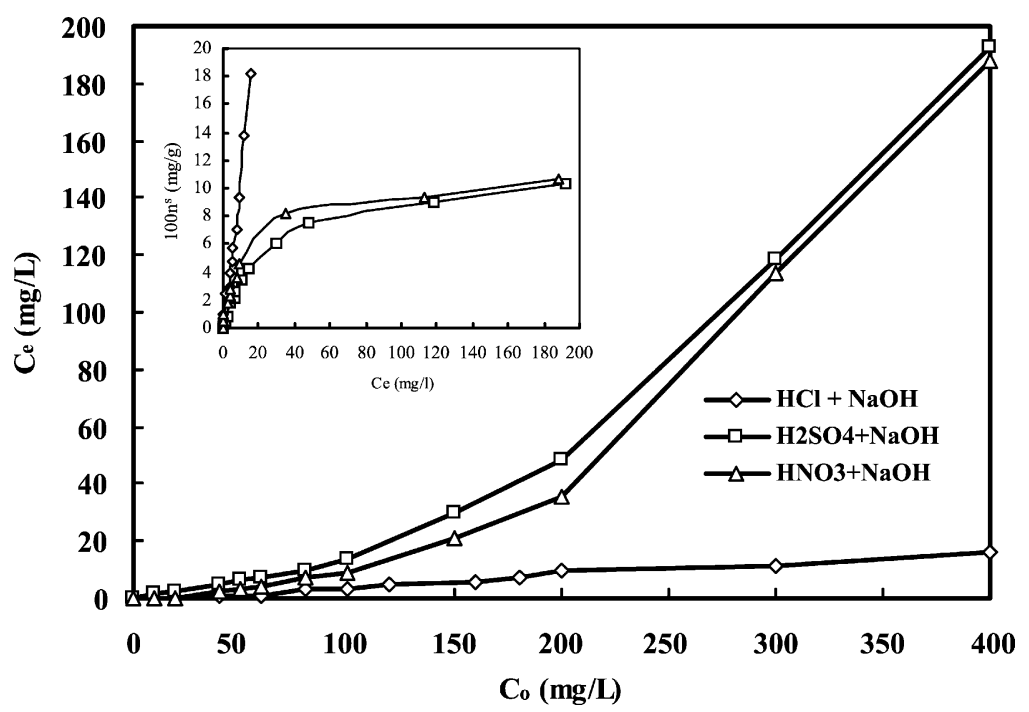

Fig. 3. Effect of anions on the decolorization of $\mathrm{ARB}$ by $2 \mathrm{~g} / 1 \mathrm{MnO} 2$ at $\mathrm{pH}=3$.

ARB concentrations were adjusted to $\mathrm{pH} 3$ with diluted $\mathrm{NaOH}$ and $\mathrm{HCl}, \mathrm{HNO}_{3}$ or $\mathrm{H}_{2} \mathrm{SO}_{4}$, respectively. The extent of the adsorption was calculated as follows:

$$
n^{\mathrm{s}}=\frac{\left(C_{0}-C_{\mathrm{e}}\right) V}{W}
$$

where $n^{\mathrm{s}}$ is the adsorbed amount (mg/g), $C_{0}$ the initial concentration, $C_{\mathrm{e}}$ the final concentration, $V$ the volume, and $W$ is the weight of $\mathrm{MnO}_{2}$.

The adsorption of ARB on $\mathrm{MnO}_{2}$ decreased dramatically when $\mathrm{SO}_{4}{ }^{2-}$ or $\mathrm{NO}_{3}{ }^{-}$was added in solution along with the azo dye, indicating the competitive nature of these anions with the dye during the adsorption process, suggesting that the sulfonic group of ARB may be the binding site for this dye on $\mathrm{MnO}_{2}$.

\subsection{Decolorization and mineralization of $A R B$ on $\mathrm{MnO}_{2}$ in the presence of ultrasonic irradiation}

The decolorization and mineralization of ARB in the presence of ultrasonic irradiation are shown in Figs. 4 and 5 (US for ultrasonic irradiation), respectively. It was apparent, as shown in Fig. 4, that the decolorization efficiency on $\mathrm{MnO}_{2}$ was much higher in the presence of ultrasonic irradiation. The decolorization efficiency was increased from 77.03 $\left(\mathrm{MnO}_{2}\right.$ alone, control) to 90.88 (oxygen atmosphere) and $94.93 \%$ (argon atmosphere), respectively. Fig. 5 showed that the TOC removal after 240 min was 11.89 (control), 48.12 (oxygen atmosphere) and $29.11 \%$ (argon atmosphere), respectively. It was clearly shown that oxygen used as saturated gas was more favorable for mineralization of the dye than argon. However, almost no decolorization of the dye was found when it was exposed to ultrasonic irradiation alone. 


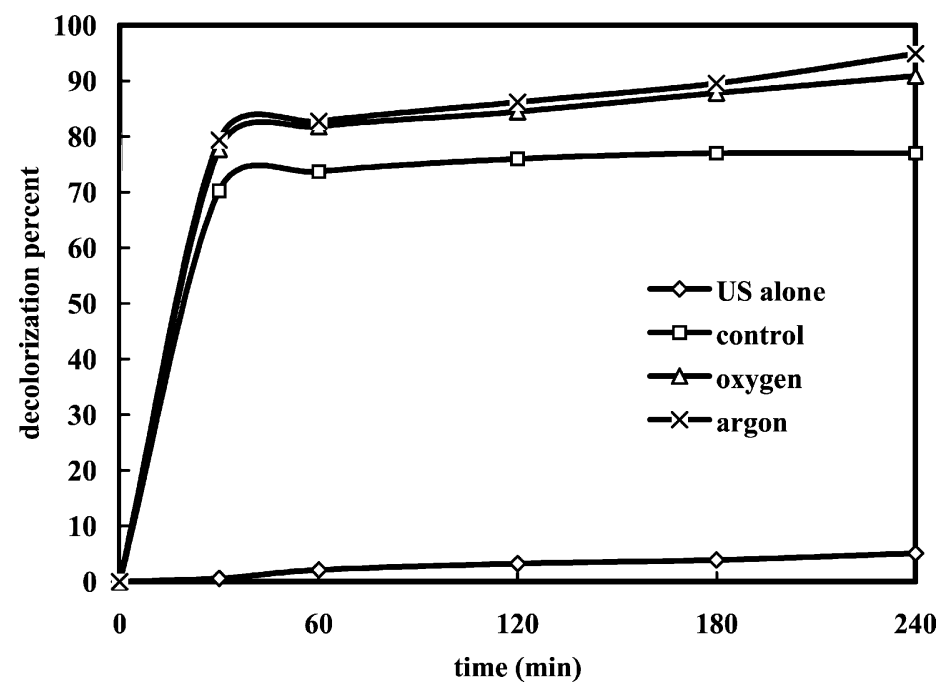

Fig. 4. Decolorization of $\mathrm{ARB}$ by $1 \mathrm{~g} / 1 \mathrm{MnO}_{2}$ at initial $\mathrm{pH}=3$ adjusted with diluted $\mathrm{NaOH}$ and $\mathrm{H}_{2} \mathrm{SO}_{4}$.

Firstly, colloidal $\mathrm{MnO}_{2}$ was readily formed during ultrasonic irradiation, which enhanced mass transfer. The average particle diameter of $\mathrm{MnO}_{2}$ was reduced from 47.5 to $3.2 \mu \mathrm{m}$ after 240 min ultrasonic irradiation of the dye- $\mathrm{MnO}_{2}$ suspension (Fig. 6). A rough calculation for increase in surface area due to decreased particle size can be made as follows.

Assumed that adsorbent particles are spheres, for a single sphere:

$$
S=\text { surface area }=\pi d^{2}
$$

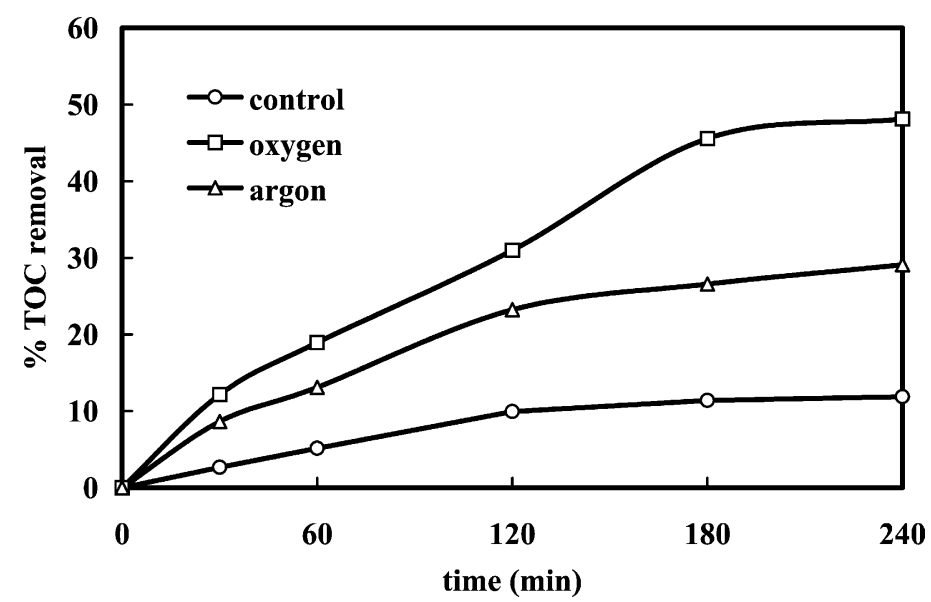

Fig. 5. TOC removal as a function of time at initial $\mathrm{pH}=3$ adjusted with diluted $\mathrm{NaOH}$ and $\mathrm{H}_{2} \mathrm{SO}_{4}, \mathrm{MnO}_{2}$ added amount $1 \mathrm{~g} / 1$. 


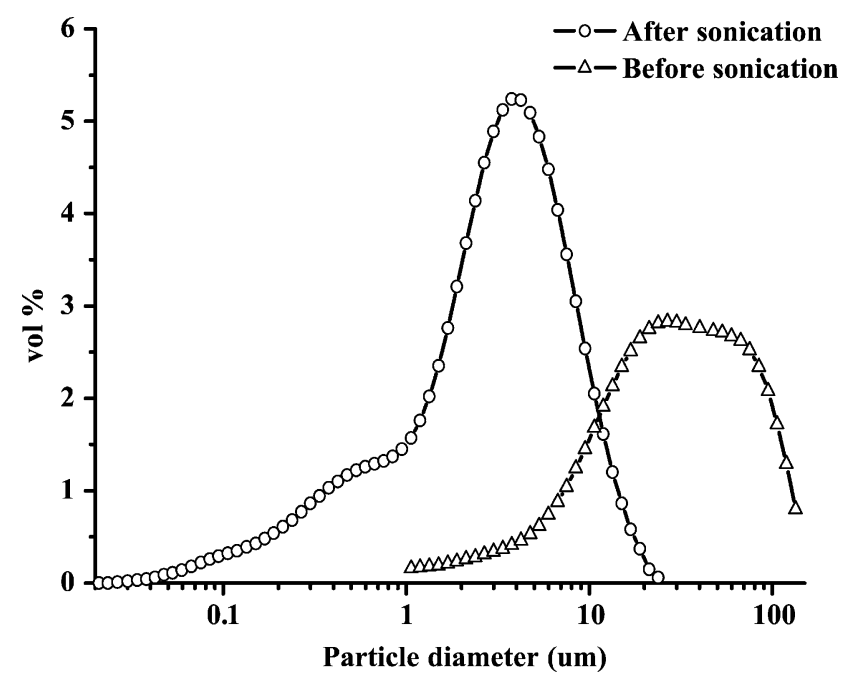

Fig. 6. Particle size reduction of $\mathrm{MnO}_{2}$ after 240-min sonication at initial $\mathrm{pH}=3$ adjusted with $\mathrm{NaOH}$ and $\mathrm{H}_{2} \mathrm{SO}_{4}$.

$$
\begin{aligned}
& V=\text { volume }=\frac{1}{6} \pi d^{3} \\
& a=\text { specific surface area }=\frac{S}{V}=\frac{6}{d}
\end{aligned}
$$

Thus, increase in surface area can be estimated as (assuming the mass of particles remains the same)

$$
S_{\text {ratio }}=\frac{a_{\text {after sonication }}}{a_{\text {before sonication }}}=\frac{d_{\text {before sonication }}}{d_{\text {after sonication }}}=\frac{47.5 \mu \mathrm{m}}{3.2 \mu \mathrm{m}}=14.84
$$

Since adsorption depends on available surface area, the adsorption capacity of ARB over $\mathrm{MnO}_{2}$ would be enhanced due to the increase of the surface area with reduced particle size for a given mass of $\mathrm{MnO}_{2}$ particles.

Secondly, ultrasonic irradiation accelerated heterogeneous reactions due to removal of the passivating outer oxide layer normally present on $\mathrm{MnO}_{2}$ surfaces via its microjetting effects $[24,25]$. Therefore, the inhibition of adsorption and oxidation of dye compound on $\mathrm{MnO}_{2}$ surface is greatly alleviated.

Most important, $\mathrm{H}_{2} \mathrm{O}_{2}$ is produced during sonication of water [26,27], which enhances the dissolution of $\mathrm{MnO}_{2}$ and replenishes the particle surface with fresh $\mathrm{MnO}_{2}$ surfaces. The dissolution rate of manganese dioxide was enhanced as shown in Fig. 7. As indicated in Fig. 7, the dissolution of manganese dioxide increased greatly in the presence of sonication, especially with argon as saturated gas.The physical phenomena leading to sonochemical effects in water are complex and not yet fully elucidated. Nevertheless, whatever the theoretical model describing the origins of the molecular activation (thermal and/or electrical), the molecules are brought to an excited state and dissociate in the interior of the bubble of 


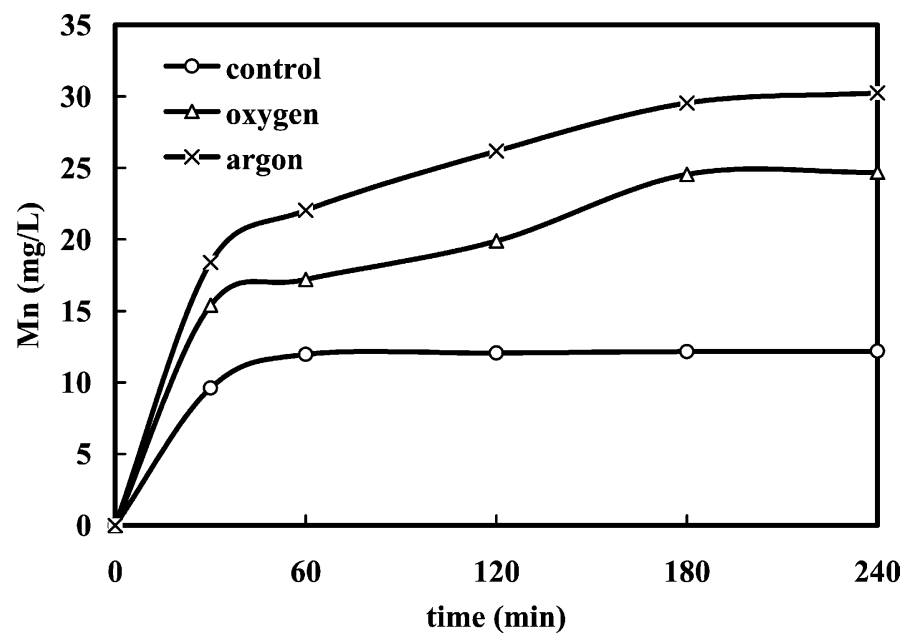

Fig. 7. Dissolution of manganese with reaction time at initial $\mathrm{pH}=3$ adjusted with $\mathrm{NaOH}$ and $\mathrm{H}_{2} \mathrm{SO}_{4}, \mathrm{MnO}_{2}$ added amount $1 \mathrm{~g} / 1$.

cavitation, which is filled with gas and vapor. The first step appears to be the cleavage of water resulting in the formation of hydroxyl and hydrogen radicals.

$$
\mathrm{H}_{2} \mathrm{O} \rightarrow \mathrm{H}^{\bullet}+\bullet \mathrm{OH}
$$

In the presence of oxygen, no hydrogen is formed. This is explained by the scavenging of $\mathrm{H}$ atoms by $\mathrm{O}_{2}$ in the gas bubbles [27]:

$$
\mathrm{H}^{\bullet}+\mathrm{O}_{2} \rightarrow \mathrm{HO}_{2}^{\bullet}
$$

The processes that lead to the formation of $\mathrm{H}_{2} \mathrm{O}_{2}$ include [16,26]:

$$
\begin{aligned}
& 2^{\bullet} \mathrm{OH} \rightarrow \mathrm{H}_{2} \mathrm{O}_{2} \\
& \mathrm{HO}_{2}^{\bullet}+\mathrm{HO}_{2}^{\bullet} \rightarrow \mathrm{H}_{2} \mathrm{O}_{2}+\mathrm{O}_{2}
\end{aligned}
$$

With $\mathrm{MnO}_{2}$ present, the following reactions can be expected to occur:

$$
\begin{aligned}
& \mathrm{MnO}_{2}+\mathrm{H}_{2} \mathrm{O}_{2}+2 \mathrm{H}^{+} \rightarrow \mathrm{Mn}^{2+}+2 \mathrm{H}_{2} \mathrm{O}+\mathrm{O}_{2} \\
& \mathrm{H}_{2} \mathrm{~L}+{ }^{\bullet} \mathrm{OH} \rightarrow \text { products }
\end{aligned}
$$

In the presence of argon at low acoustic frequency, the hydrogen peroxide formation rate is higher [28,29], while more hydroxyl radicals are produced if the solution is saturated with oxygen [16]. Hence, more ${ }^{\bullet} \mathrm{OH}$ is scavenged by both $\mathrm{H}_{2} \mathrm{O}_{2}$ and $\mathrm{H}$ to form $\mathrm{H}_{2} \mathrm{O}$ with argon as saturated gas, which was not favorable for mineralization of the dye as compared with oxygen. It should also be pointed out that ${ }^{\circ} \mathrm{OH}$ could be scavenged by excess amount of $\mathrm{Mn}^{2+}$, which needs further investigation to find out the optimum amount of $\mathrm{MnO}_{2}$ needed in the future work. 


\section{Conclusion}

The decolorization of azo dye ARB on manganese dioxide in the absence/presence of ultrasonic irradiation has been studied. The decolorization process is highly $\mathrm{pH}$ dependent, with increased efficiency at decreasing $\mathrm{pH}$ values. Counteranions such as $\mathrm{SO}_{4}{ }^{2-}$ and $\mathrm{NO}_{3}{ }^{-}$ greatly inhibit the decolorization process, indicating the competitive nature of these anions with the dye during the adsorption process. The decolorization efficiency is much higher in the presence of ultrasonic irradiation than using $\mathrm{MnO}_{2}$ alone. Moreover, oxygen used as saturated gas is more favorable for mineralization of the dye. It is feasible to incorporate ultrasonic irradiation and $\mathrm{MnO}_{2}$ for degradation of azo dyes, both for decolorization and mineralization of the dye. Given the acidic nature of the final solution, some form of the neutralization would probably be necessary before eventual discharge.

\section{Acknowledgements}

The authors wish to thank the Natural Sciences Foundation of China (No. 59838300) and National Outstanding Youth Scientific Foundation (No. 50225824) for funding these studies.

\section{References}

[1] W.G. Kuo, Decolorizing dye wastewater with Fenton's reagent, Wat. Res. 26 (1992) 881-886.

[2] R. Andreozzi, V. Caprio, A. Insola, R. Morotta, R. Sanchirico, Advanced oxidation processes for the treatment of mineral oil-contiminated wastewaters, Wat. Res. 34 (2000) 620-628.

[3] E.R. Carraway, A.J. Hoffmann, M.R. Hoffmann, Photocatalytic oxidation of organic acids on quantum-sized semiconductor colloids, Environ. Sci. Technol. 28 (1994) 786-793.

[4] A.P. Davis, C.P. Huang, The removal of substituted phenols by a phoyocatalytic oxidation process with cadmium sulfide, Wat. Res. 24 (1990) 543-550.

[5] D.F. Ollis, E. Pelizzetti, N. Serpone, Destruction of water contaminants, Environ. Sci. Technol. 25 (1991) $1523-1529$.

[6] J.M. Herrmann, C. Guillard, P. Pichat, Heterogeneous photocatalysis: an emerging technology for water treatment, Catal. Today 17 (1993) 7-20.

[7] M.R. Hoffmann, S.T. Martin, W. Choi, D.W. Bahnemann, Environmental applications of semiconductor photocatalysis, Chem. Rev. 95 (1995) 69-96.

[8] T.M. Olson, P.F. Barbier, Oxidation kinetics of natural organic matter by sonolysis and ozone, Wat. Res. 28 (1994) 1383-1391.

[9] I. Hua, M.R. Hoffmann, Optimization of ultrasonic irradiation as an advanced oxidation technology, Environ. Sci. Technol. 31 (1997) 2237-2243.

[10] Y. Ku, K.-L. Chen, K.-C. Lee, Ultrasonic destruction of 2-chlorophenol in aqueous solution, Wat. Res. 31 (1997) 929-935.

[11] K. Vinodgopal, J. Peller, O. Makogon, P.V. Kamat, Ultrasonic mineralization of a reactive textile azo dye, Wat. Res. 32 (1998) 3646-3650.

[12] B. David, M. Lhote, P. Boule, Ultrasonic and photochemical degradation of chlorpropham and 3-chloroaniline in aqueous solution, Wat. Res. 32 (1998) 2451-2461.

[13] D. Drijvers, H.V. Langenhove, M. Beckers, Decomposition of phenol and trichloroethylene by the ultrasound $/ \mathrm{H}_{2} \mathrm{O}_{2} / \mathrm{CuO}$ process, Wat. Res. 33 (1999) 1187-1194.

[14] J.D. Schramm, I. Hua, Ultrasonic irradiation of dichlorvos: decomposition mechanism, Wat. Res. 35 (2001) 665-674. 
[15] K.S. Suslick, Ultrasound: Its Chemical, Physical, and Biological Effects, VCH, New York, 1988.

[16] C. Petrier, M. Lamy, A. Francony, A. Benahcene, B. David, Sonochemical degradation of phenol in dilute aqueous solutions: comparison of the reaction rates at 20 and $487 \mathrm{kHz}$, J. Phys. Chem. 98 (1994) 1051410520.

[17] Y. Nagata, M. Nakagawa, H. Okuno, Y. Mizukoshi, B. Yim, Y. Maeda, Sonochemical degradation of chlorophenols in water, Ultrason. Sonochem. 7 (2000) 115-120.

[18] A.T. Stone, J.J. Morgan, Reduction and dissolution of manganese(III) and manganese(IV) oxides by organics. 2. Survey of the reactivity of organics, Environ. Sci. Technol. 18 (1984) 617-624.

[19] W.G. Sunda, D.J. Kieber, Oxidation of humic substances by manganese oxide yields low-molecular-weight organic substances, Nature 367 (1994) 62-64.

[20] R. Liu, H. Tang, Oxidative decolorization of direct light red F3B dye at natural manganese mineral surface, Wat. Res. 34 (2000) 4029-4035.

[21] T.D. Waite, I.C. Wrgley, R. Szymczak, Photoassisted dissolution of a colloidal manganese oxide in the presence of fulvic acid, Environ. Sci. Technol. 22 (1988) 778-785.

[22] A.T. Stone, Reduction and dissolution of manganese (III/IV) oxides by substituted phenols, Environ. Sci. Technol. 21 (1987) 979-988.

[23] P. Mulvaney, L. Denison, F. Grieser, R. Cooper, J.V. Sanders, D. Meisel, Radiation-induced dissolution of colloidal manganese oxides, J. Colloi. Interface Sci. 121 (1988) 71-80.

[24] K.S. Suslick, D.J. Casadonte, Heterogeneous catalysis with nickel powder, J. Am. Chem. Soc. 109 (1987) 3459-3461.

[25] T.J. Mason, A. Newman, J.P. Lorrimer, J. Lindey, K. Hutt, Ultrasonically assisted catalytic decomposition of aqueous sodium hypochlorite, Ultrason. Sonochem. 3 (1996) 53-55.

[26] E.J. Hart, A. Henglein, Free radical and free atom reactions in the sonolysis of aqueous iodine and formate solutions, J. Phys. Chem. 89 (1985) 4342-4347.

[27] A. Kotronarou, G. Mills, M.R. Hoffmann, Ultrasonic irradiation of $p$-nitrophenol in aqueous solution, J. Phys. Chem. 95 (1991) 3630-3638.

[28] C. Petrier, A. Jeunet, J.-L. Luche, G. Reverdy, Unexpected frequency effects on the rate of oxidative processes induced by ultrasound, J. Phys. Chem. 114 (1992) 3148-3150.

[29] S.I. Nikitenko, Isotope effect in hydrogen peroxide formation during $\mathrm{H}_{2} \mathrm{O}$ and $\mathrm{D}_{2} \mathrm{O}$ sonication, Ultrason. Sonochem. 7 (2000) 249-253. 